\title{
Eosinophilic hepatitis mimicking hepatic metastases - a case report
}

\begin{abstract}
Focal eosinophilic infiltration is a rare disease entity that in patients with malignancies may mimic malignant hepatic nodules. Eosinophilic hepatitis is associated with a variety of disorders such as parasitic infestations, allergic conditions, internal malignancies, drug hypersensitivity, and hypereosinophilic syndrome. In daily clinical practice, eosinophilic abscess with typical or atypical imaging findings can mimic metastasis. We hereby report a patient of eosinophilic hepatitis that mimicked hepatic metastases.
\end{abstract}

Keywords: parasitic infestations, allergic conditions, internal malignancies, drug hypersensitivity, hypereosinophilic syndrome
Volume 5 Issue 2 - 2018

\author{
Ritu Chandra, Sandeep Agarwal, Vandana \\ Arora,Vibhu Mittal \\ Department of Radiation Oncology, Pathology, \\ Gastroenterology, India
}

Correspondence: Ritu Chandra, Department of Radiation Oncology, Pathology, Gastroenterology, Max Super Speciality Hospital,Vaishali, Ghaziabad, Uttar Pradesh, India, Tel 919958495453,Email ritu73I@gmail.com

Received: February 24, 2018 | Published: April 03, 2018

\section{Case report}

A 65 year old male presented with complaints of pricking sensation in the left side of throat for two months that got aggravated on feeding. CECT Face and neck reported faintly enhancing thickening measuring approximately $3.2 \times 2 \times 1.4 \mathrm{~cm}$ in the left pyriform sinus and enlarged necrotic left cervical level II and III lymph nodes measuring approximately $0.8 \times 1.6 \mathrm{~cm}$ and $0.9 \times 1.5 \mathrm{~cm}$. Biopsy from growth in left pyriform fossa reported squamous cell carcinoma .Upper GI Endoscopy was done and reported irregular growth seen in left pyriform fossa. USG Whole abdomen reported multiple hypoechoic space occupying lesions in segment VI/VII of right lobe of liver, largest measuring $2.1 \times 1.7 \mathrm{~cm}$ likely suggestive of metasatsis. FNAC from liver space occupying lesions revealed paucicellular smears with presence of few benign hepatocytes and occasional stromal fragment in a haemorrhagic background. USG guided true cut biopsy from liver space occupying lesions showed fragmented cores of liver displaying five portal tracts. Sheets of eosinophils were seen infiltrating the hepatic lobules. Focal necrosis with palisading histiocytes were seen. Portal tracts showed moderate mixed inflammation comprising of lymphocytes, neutrophils and eosinophils. These features were suggestive of eosinophilic hepatitis.

Patient was planned for concurrent chemoradiation.He was given a course of Antihelminthics. He developed difficulty in breathing, cough with expectoration and generalized weakness during the treatment. CECT Thorax was done that reported mild paraseptal and centrilobular emphysematous changes in bilateral lungs, mild fibrotic densities in bilateral apical lung regions and para tracheal air cyst. USG Whole Abdomen was also done which did not show any focal space occupying lesion in liver or dialatation of IHBR.

\section{Discussion}

In many literature reports, ${ }^{1-6}$ several terms, such as "foci of eosinophil-related necrosis," "focal eosinophilic infiltration," "focal eosinophilic necrosis," and "eosinophilic abscess" have been used for eosinophil-related hepatic lesions. These terms have not yet been clearly defined histopathologically. In general, eosinophilic abscess means eosinophilic infiltration with focal necrosis, and focal eosinophilic infiltration means eosinophilic infiltration without focal necrosis.

The imaging findings of eosinophilic abscess or focal eosinophilic infiltration are well known and are usually similar regardless of the cause. On CT, eosinophilic abscess or focal eosinophilic infiltration usually appears as small, oval or round, and low attenuating nodules with well- or ill-defined margins. They are most conspicuous during the portal venous phase. They have iso/low, low/low, or mixed attenuation on the hepatic arterial/portal venous phases. ${ }^{1-3,5-8}$ On sonographic examination, they manifest as small (usually $<2 \mathrm{~cm}$ ), poorly or well-defined, oval or round, low echoic nodules without hyper or hypoechoic rims. On histopathology, eosinophilic abscess or focal eosinophilic infiltration is related to perivascular infiltration of eosinophils, predominantly in the periportal space, and hepatocellular necrosis. . $, 3,5,9,10$ We can speculate that portal flow obstruction by eosinophilic infiltration makes focal eosinophilic infiltration or eosinophilic abscess hypoattenuation on portal phase $\mathrm{CT}$, and inflammatory hyperemia or compensatory arterial overflow causes enhancement on arterial phase CT and MRI. In summary, focal eosinophilic liver disease may be confused with those of liver malignancy, careful analysis with imaging and subsequent FNAC or biopsy from the lesion is mandatory.

\section{Acknowledgements}

None.

\section{Conflict of interest}

The author declares that there is no conflict of interest. 


\section{References}

1. Lee WJ, Lim HK, Lim JH, et al. Foci of eosinophil-related necrosis in the liver: imaging findings and correlation with eosinophilia. AJR. 1999;172(5):1255-1261.

2. Yoo SY, Han JK, Kim YH, et al. Focal eosinophilic infiltration in the liver: radiologic findings and clinical course. Abdom Imaging. 2003;28(3):326332.

3. Jang HJ, Lee WJ, Lee SJ, et al. Focal eosinophilic necrosis of the liver in patients with underlying gastric or colorectal cancer: CT differentiation from metastasis. Korean J Radiol. 2002;3(4):240-244.

4. Kim GB, Kwon JH, Kang DS. Hypereosinophilic syndrome: imaging findings in patients with hepatic involvement. AJR. 1993;161(3):577-580.
5. Lim JH, Lee WJ, Lee DH, et al. Hypereosinophilic syndrome: CT findings in patients with hepatic lobar or segmental involvement. Korean J Radiol. 2000;1(2):98-103.

6. Cho DH, Chang JC, Seong KH. Dynamic CT findings of eosinophilic hepatic abscess and its clinical course. $J$ Korean Radiol Soc. 1996;35(6):899-904.

7. Won JH, Kim MJ, Kim BM, et al. Focal eosinophilic infiltration of the liver: a mimick of hepatic metastasis. Abdom Imaging 1999;24(4):369 372 .

8. Kwak HS, Han YM, Lee JM. Focal eosinophilic infiltration of the liver mimicking heaptocellular carcinoma. Clin Imaging. 2004;28(1):36-39. 